\title{
Preconceptional ancestry-based carrier couple screening for cystic fibrosis and haemoglobinopathies: what determines the intention to participate or not and actual participation?
}

\author{
Phillis Lakeman*,1,4, Anne Marie Catharina Plass ${ }^{1,4}$, Lidewij Henneman ${ }^{2,4}$, \\ Pieter Dirk Bezemer ${ }^{3,4}$, Martina Cornelia Cornel ${ }^{1,4}$ and Leo Pieter ten Kate ${ }^{1,4}$
}

\author{
${ }^{1}$ Department of Clinical Genetics, VU University Medical Center, Amsterdam, The Netherlands; ${ }^{2}$ Department of Public \\ and Occupational Health, VU University Medical Center, Amsterdam, The Netherlands; ${ }^{3}$ Department of Clinical \\ Epidemiology and Biostatistics, VU University Medical Center, Amsterdam, The Netherlands; ${ }^{4} E M G O$ Institute, VU \\ University Medical Center, Amsterdam, The Netherlands
}

This paper explores determinants of the intention to participate or not and of actual participation in preconceptional ancestry-based carrier couple screening for cystic fibrosis (CF) and haemoglobinopathies (HbPs). In total, 9453 individuals from a multi-ethnic population were invited. Invitees who had a partner and who were planning a pregnancy were the target population (33-36\%). Test participation was conditional on survey participation. Those who refrained from test participation were asked to participate in the survey only. The questionnaire was based on the Theory of Planned Behaviour, which explains behaviour through intention. It was completed by 418 survey participants: 171 who intended to participate in the testing, and 247 who refrained from test participation. Both test intenders and offer decliners generally had a positive attitude towards test participation, and perceived high behavioural control. This applied to Western and non-Western survey participants equally. Offer decliners, however, perceived less control in terms of the time and effort needed for participation. Still, $68 \%$ of them intended to participate in the future if the screening would be offered routinely. Test intenders more often would draw reproductive consequences from test results, perceived a higher risk of being a carrier, more benefits and less adverse psychological outcomes. Feelings of stigmatisation were not an important issue, but $14 \%$ thought that there would be discrimination against carriers: among them more were non-Western survey participants. Preconceptional ancestry-based CF and HbPs carrier screening was evaluated as positive and desirable among Western and non-Western survey participants. The effort and time needed for participation were important reasons for declining participation, which might be overcome by improving access to the screening.

European Journal of Human Genetics (2009) 17, 999-1009; doi:10.1038/ejhg.2009.1; published online 18 February 2009

Keywords: preconceptional; carrier screening; cystic fibrosis; haemoglobinopathies; ancestry; participation

*Correspondence: Dr P Lakeman, Department of Clinical Genetics, EMGO Institute, VU University Medical Center, Boelelaan 1117, P.O. Box 7057, 1007 MB Amsterdam, The Netherlands. Tel: +31 20 4440150; Fax: + 3120 4440769. E-mail: p.lakeman@vumc.nl

Received 23 January 2008; revised 25 November 2008; accepted 8 January 2009; published online 18 February 2009 


\section{Introduction}

Cystic fibrosis (CF) and haemoglobinopathies (HbPs), including sickle cell disorders and thalassaemia, are severe and relatively common autosomal recessive disorders according to ancestry. CF is found predominantly in people who originate from Europe, North Africa, Turkey, the Middle East, and the former Soviet Union. ${ }^{1,2}$ HbPs are mainly found in people with ancestors from Africa, the Mediterranean area, the Middle East, parts of the Indian sub-continent, and South-East Asia., ${ }^{3,4}$ Preconceptional carrier couple screening for these disorders enables prospective parents to make reproductive decisions before pregnancy. However, in the Netherlands, as in many other European countries, this kind of screening is not current practice and there has been debate about whether it should be introduced, and if so, how. ${ }^{5-8}$ In earlier studies targeted ancestry-based carrier screening for these disorders has been advised..$^{9-11}$ However, after the implementation of sickle cell screening in the United States in the early 1970 s, $^{12,13}$ negative experiences such as discrimination and stigmatisation of carriers resulted in hesitations towards targeted ancestry-based screening. A combined offer of ancestry-based CF and HbPs carrier couple screening reduces the potential risk of stigmatisation or discrimination of sub-populations, because almost every couple, irrespective of their ancestry, will be eligible for some form of carrier screening: for $\mathrm{CF}, \mathrm{HbPs}$, or both disorders. Furthermore, studying an offer of preconceptional carrier screening for these disorders may serve as a model for preconceptional carrier screening for other genetic disorders as well.

This study is part of a project in which a unique offer of combined ancestry-based preconceptional CF and/or HbPs carrier couple screening was actually made in a multi-ethnic population in the Netherlands. The test uptake among those invitees who had a partner and who were planning a pregnancy was estimated to be $3 \% .{ }^{14}$ It is generally known that uptake in carrier-screening programmes is far from $100 \% .^{15-17}$ For example, in an earlier preconceptional CF carrier couple screening study in the Netherlands, ${ }^{5} 25 \%$ of the prospective parents who had been invited participated in the screening. As participation in screening must be voluntary and based on an informed decision, ${ }^{18}$ uptake should never be the only focus of offering a screening programme. Nevertheless, in this project, it was expected beforehand that not all invited prospective parents would participate in the screening. Therefore, besides uptake, we studied those factors that determined the decision to accept or decline participation in this study on preconceptional ancestry-based carrier screening offer for $\mathrm{CF}$ and/or HbPs.

Factors affecting the decision to accept or decline carrier screening for CF have recently been reviewed by Chen et al. ${ }^{15}$ Important acceptance factors included 'higher perceived benefits' (eg, not having an affected child, knowing one's carrier status), 'weaker perceptions of barriers' (eg, social stigma, psychological harm), and 'having fewer or no children'. Acceptance factors reported elsewhere were lower perceived negative consequences of test results, ${ }^{17}$ more knowledge, ${ }^{16,17,19}$ strong perception of the severity of the disease, ${ }^{15,20,21}$ high perceived susceptibility, 15,22,23 and higher socioeconomic status, female gender, and age. ${ }^{15}$ Important factors for declining, reported by Chen et al., ${ }^{15}$ included perceived barriers to obtain the screening, higher parity, lack of knowledge, and weaker perceptions of benefits. Other factors for declining mentioned elsewhere were attitudes towards abortion, perceived severity of carrier status, low perceived susceptibility, and ethnicity. ${ }^{15,19,20,24-26}$ Chen et al. ${ }^{15}$ further noticed a lack of theoretical frameworks in studies investigating the determinants of participation in carrier screening. In this study, however, the Theory of Planned Behaviour (TPB) ${ }^{27}$ was applied (Figure 1). The TPB has proven to offer a useful framework in explaining and predicting health behaviour or refraining from that specific behaviour. ${ }^{28}$ According to the TPB, behaviour is explained by intention, which in turn is explained by attitude, social influence, and perceived behavioural control. ${ }^{27}$ The latter is also a direct determinant of behaviour. In this study, the TPB was used to explore the intention to participate in preconceptional ancestry-based $\mathrm{CF}$ and/or HbPs carrier couple screening. The following research questions were addressed: (1) Which are the determinants of the intention to participate or not? (2) What determined actual test participation? (3) What determined the intention to participate in future screening of this kind, whether this became possible, among those who refrained from current test participation? (4) Do these determinants differ between participants of Western and non-Western origin?

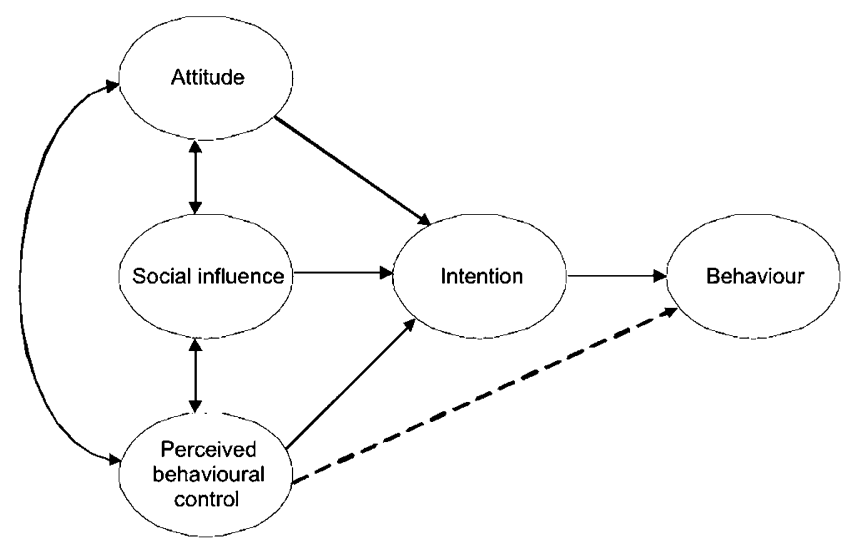

Figure 1 The Theory of Planned Behaviour. 


\section{Methods \\ Design}

From January to December 2005, 9453 individuals (20-35 years) in Amsterdam, The Netherlands, including 50-60\% non-Western immigrants, received an invitation to participate in preconceptional ancestry-based CF and/or HbPs carrier couple screening. They were invited by either their own general practitioner (GP), who selected the names and addresses of the 20- to 35-year-olds from the practice register, or by the Municipal Health Service, which obtained these data from the population register. Enclosed with the letter of invitation were an information leaflet, a reply form, and a decisional instrument. The information leaflet described the clinical and genetic aspects of the disorders, the carrier prevalence in different populations according to ancestry, the pros and cons of participation, the test sensitivity, and the test procedure. Invitees who had a partner with whom they were planning a pregnancy were defined as the target population. On the reply form it was first asked whether the invitee had a partner. Those who had a partner were further asked whether they wanted to participate in (a) the screening study, which included test participation and participation in a questionnaire survey, or (b) in the survey only, or (c) not at all. Test participation without survey participation was not allowed. Eligibility for the CF and/or HbP test(s) was based on both partners' ancestral origin and was assessed by the enclosed decisional instrument. ${ }^{29}$ The tests were offered free of charge. All the study materials were available only in the Dutch language. Exclusion criteria for participation were pregnancy, inability to read and write Dutch, and a positive family history of $\mathrm{CF}$ and/or HbPs, in which case the couple was referred to a clinical genetics centre.

Invitees who returned the reply form were further referred as respondents and those who did not as nonrespondents (see Figure 2). Respondents who belonged to the target population were divided into those who had the intention to participate in the carrier-screening test(s) (ie, offer acceptors) and those who refrained from current test participation (ie, offer decliners). Those who wished to participate in the carrier-screening test(s) were invited to visit their GP with their partner within 1 month for pre-test consultation. Both of them were asked to complete a questionnaire (see below) in the GP's waiting room before pre-test consultation. Offer decliners who had stated on the reply form that they were willing to participate in the survey only were sent two copies of the questionnaire at home. At the GP's practice the sampling for the CF and/or HbPs carrier test(s), based on the above-mentioned decisional instrument, ${ }^{29}$ was carried out. The actual testing in the laboratory started only after a signed informed consent form had been received. The study protocol was approved by the Medical Ethics Committee of the VU University Medical Center in Amsterdam.

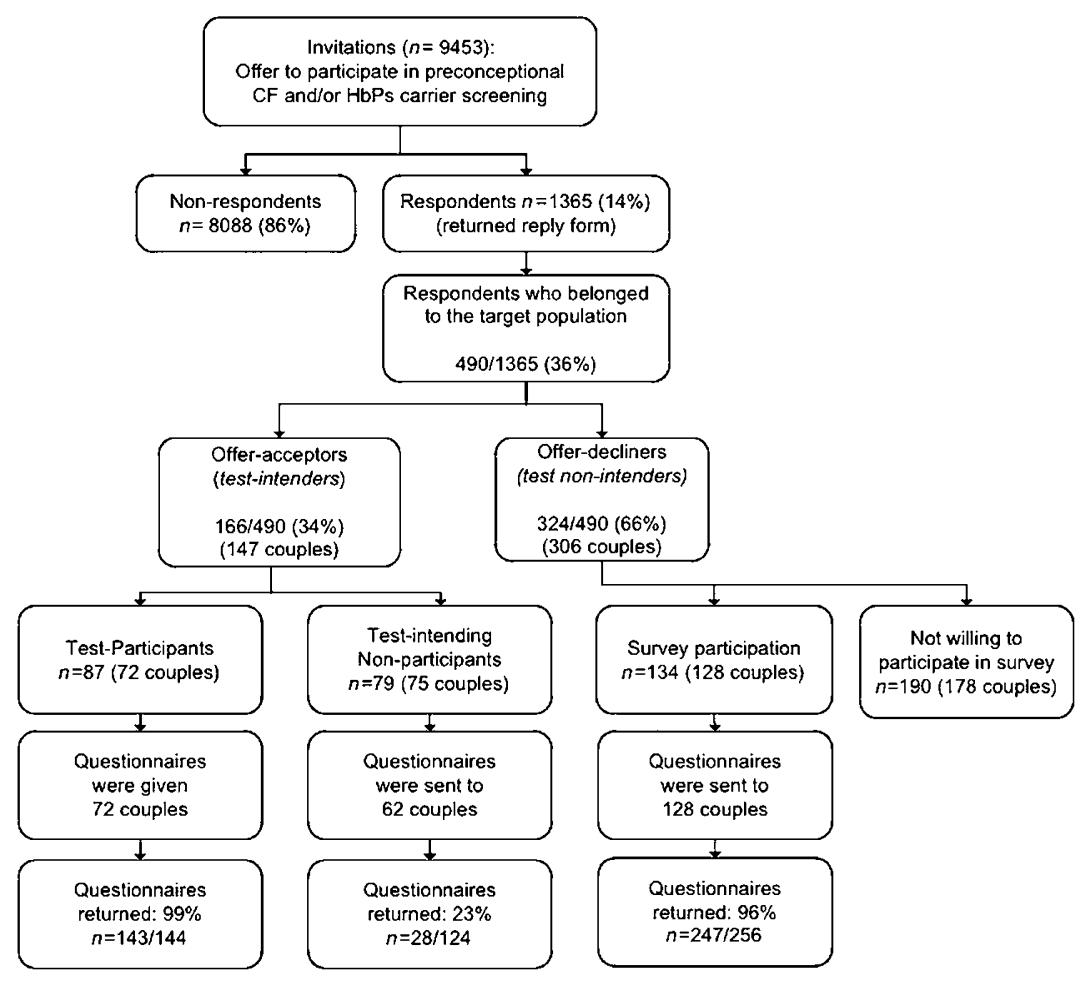

Figure 2 Response to the offer of preconceptional CF and/or HbPs carrier screening. 


\section{Questionnaire}

Each partner in a couple was asked to complete a structured questionnaire, without conferring with their partner. All survey participants, irrespective of their ancestry, were asked to complete all questions. The structured questionnaire, which was developed to address the research questions, was mainly based on the $\mathrm{TPB},{ }^{27}$ in addition to other variables that were expected to explain intention to test participation. ${ }^{15,17,20,21}$ All variables are presented in Table 1 , as well as their corresponding items, and the answer format. For each scale, factor analysis with direct oblimim rotation was performed to investigate whether items were loaded on one or more component(s). Reliability analysis was applied to each scale to determine whether the set of items was homogeneous (Cronbach's $\alpha \geq 0.60$, see Table 1 ). Unless stated otherwise, the individual items were measured on a 5-point Likert scale, and were recoded if necessary: a score of 1 indicated a negative/ unfavourable score and a score of 5 indicated a positive/ favourable score, except for 'psychological impact', 'stigmatisation', and 'feelings of eugenics'. For these variables a score of 1 indicated a positive/favourable score, representing the absence of negative psychological impact, stigmatisation and feelings of eugenics, and a score of 5 corresponded to a negative/unfavourable score, representing the presence of negative psychological impact, stigmatisation, and feelings of eugenics.

Future intention among decliners of current offer Offer decliners were asked whether they would participate in preconceptional CF and/or HbPs carrier screening in the future if this became possible. A 'future intention' scale was constructed, based on three items: (1) 'would you consider having a carrier test in the future if the preconceptional CF and HbPs carrier screening became a standard offer to all couples planning a pregnancy?'(answer format: no/probably not/not sure/probably/yes); and the two items of the variable 'perceived benefits': (2) 'I would want to prevent the birth of a child with $\mathrm{CF}$, sickle cell disease and/or thalassemia' and (3) 'I want to get more reassurance about my chance of having a child with CF, sickle cell disease and/or thalassemia'. All these three were loaded on one factor, and Cronbach's $\alpha$ was 0.71 .

Ancestry On the basis of their own and parental native countries we distinguished participants of (1) Western origin, who have their ancestry in Europe (including the Netherlands), North America, and Australia, and who are mainly eligible for CF carrier screening, and (2) nonWestern origin, including people from Turkey, Surinam, Morocco, and the Netherlands Antilles, who form the four largest immigrant groups in the Netherlands, ${ }^{30,31}$ and who are eligible for HbPs carrier screening. Couples from Turkey and Morocco were eligible for both the CF and HbPs carrier-screening tests. ${ }^{29}$

\section{Data analysis}

Both partners in a couple were treated as independent participants, because earlier research showed that individual partners provide different information. ${ }^{17,32}$ Wilcoxon and Mann-Whitney tests were used to compare the mean scores between groups. For each variable we calculated the proportion of survey participants who had a score below/ above 3 (the neutral point). The chi-square test was used for the statistical comparison of proportions. All analyses were performed in SPSS 14.0 for Windows. Hierarchical linear regression analysis was applied stepwise to investigate which variables determined the intention to participate in the current preconceptional carrier testing. The predictive power of the TPB determinants (step 1), the other variables mentioned in Table 1 (step 2), and the sociodemographic variables (step 3) was investigated. In addition, only among offer decliners, the same analysis was performed to investigate which variables determined future intention to participate in the screening. Finally, only among offer acceptors, this analysis was performed to investigate which variables determined actual test participation.

\section{Results \\ Response}

In Figure 2, a flow chart of the response to the invitation is presented. Fourteen percent $(1365 / 9453)$ of the invitees returned the reply form, 490 of whom belonged to the target population (36\%). There were 166 offer acceptors, representing 147 couples (in 19 couples both partners had received the invitation). Of these 147 couples, actually 72 participated in the testing. The remaining 75 couples, who were called test-intending non-participants because they finally had not participated in the testing in spite of their positive intention, were contacted by telephone. They were told that testing was no longer possible and were asked to at least complete the questionnaire, as they initially had agreed with survey participation as well. Of them, 62 couples agreed with sending two copies of the questionnaire. Among the 324 offer decliners, 134 (representing 128 couples) were willing to participate in the survey only. In total, 262 couples received two identical copies of the questionnaire, of which $80 \%(418 / 524)$ were returned by $99 \%(143 / 144)$ of the test participants, by $23 \%(28 / 124)$ of the test-intending non-participants, and by $96 \%(247 / 256)$ of the offer decliners. Table 2 represents the sociodemographic characteristics of these 418 survey participants. Offer decliners more often had children and a higher level of education than offer acceptors.

\section{Determinants of the intention to participate or not and of actual participation}

Mean scores The survey participants generally had positive/favourable mean scores on all variables that were included in the questionnaire (see Table 3). They generally 
Table 1 Construct of the questionnaire: scales with corresponding items and single items

\begin{tabular}{|c|c|c|}
\hline Variables/scales & Cronbach's $\alpha$ & Statements/items \\
\hline $\begin{array}{l}\text { Theory of Planned Behaviour } \\
\text { Attitude }^{\mathrm{a}}\end{array}$ & 0.85 & $\begin{array}{l}\text { I think that participating in carrier screening for cystic fibrosis, sickle cell disease and/ } \\
\text { or thalassemia before pregnancy, if my partner and I are eligible for screening, is... } \\
\text { Good-bad } \\
\text { Important-unimportant } \\
\text { Alarming-reassuring (emotional) } \\
\text { Sensible-unwise } \\
\text { Undesirable-desirable } \\
\text { Pleasant-unpleasant (emotional) } \\
\text { Discriminatory-a privilege } \\
\text { Harmful-beneficial }\end{array}$ \\
\hline Social influence & 0.84 & $\begin{array}{l}\text { I think that... } \\
\text { My partner thinks that we should participate in the screening } \\
\text { My family... } \\
\text { My friends... } \\
\text { My neighbours... } \\
\text { I am afraid that people will look differently at me if I had a child with CF, sickle cell } \\
\text { disease and/or thalassemia }\end{array}$ \\
\hline Perceived behavioural control $^{\mathrm{b}}$ & 0.73 & $\begin{array}{l}\text { I am not capable of participating in carrier screening if blood needs to be taken from } \\
\text { me with a needle (external control) } \\
\text { I am not capable of participating in carrier screening if I need to wash out my mouth } \\
\text { with salt water (external control) } \\
\text { It costs me too much effort to participate in the carrier screening (internal control) } \\
\text { It costs me too much time to participate in the carrier screening (internal control) } \\
\text { I am reluctant to participate in the carrier screening (internal control) }\end{array}$ \\
\hline
\end{tabular}

\section{Additional variables}

Perceived benefits

Reproductive consequences of test results

Severity of the disorders

Perceived susceptibility (risk perception)

Psychological impact

Stigmatisation

Feelings of eugenics
I would want to prevent the birth of a child with CF, sickle cell disease and/or thalassemia

I want to get more reassurance about my chance of having a child with $\mathrm{CF}$, sickle cell disease and/or thalassemia

$0.79 \quad$ I am against the abortion of a child with CF

I am against the abortion of a child with sickle cell disease or thalassemia The test results will not influence my reproductive behaviour

$\mathrm{CF}$ is a severe disorder

Sickle cell disease and thalassemia are severe disorders

0.83 At this moment I am feeling worried about being a carrier of CF, sickle cell disease and/or thalassemia At this moment I am feeling worried about having a child with $C F$, sickle cell disease and/or thalassemia

I think there is a high chance that I am a carrier of CF

I think there is a high chance that I am a carrier of sickle cell disease and/or thalassemia

\section{I think that offering these carrier test(s) will cause anxiety}

I think that by offering these carrier test(s) people will be burdened with unwanted information

I think it is annoying that I am expected to think about these carrier test(s) before a pregnancy

0.73 I would feel less healthy if I was a carrier

I think people will see me in a different light if I was a carrier

I think I would be subject to discrimination if I was a carrier

0.60 The carrier tests create too high expectations about the birth of a healthy child I am afraid that the carrier tests will contribute to the development of the perfect human being 
Table 1 (Continued)

\begin{tabular}{|c|c|c|}
\hline Variables/scales & Cronbach's $\alpha$ & Statements/items \\
\hline Knowledge about inheritance & & $\begin{array}{l}\text { A carrier of CF can also have CF } \\
\text { (Yes, I agree/no, I do not agree/I don't know) } \\
\text { A carrier of sickle cell disease or thalassemia, can also have these disorders } \\
\text { (Yes, I agree/no, I do not agree/I don't know) } \\
\text { It is possible to be a carrier of CF or HbPs when these disorders are not present in } \\
\text { your family } \\
\text { (Yes, I agree/no, I do not agree/I don't know) } \\
\text { In which situation do parents have a high risk of having a child with CF or HbPs? } \\
\text { (If both partners are carriers/if just one partner is a carrier/l don't know) } \\
\text { What is the chance of having a child with CF or HbPs when both partners are carriers? } \\
(100 \% / 50 \% / 25 \% / / \text { don't know) }\end{array}$ \\
\hline
\end{tabular}

Other questions

Familiarity with the disorders

Familiarity with the

carrier tests

Religion
Have you ever heard of CF or do you know someone with CF? (Yes/no) Have you ever heard of sickle cell disease or thalassemia or do you know someone with (one of) these disorders? (Yes/No)

Have you ever heard of a carrier screening test for CF? (Yes/no)

Have you ever heard of a carrier screening test for sickle cell disease or thalassemia? (Yes/no)

Did your religion influence your decision to participate or not to participate? (Yes/no/I have no religion)

${ }^{a}$ Attitude was constructed from two components: one with an emotional (two items) and another with an instrumental/cognitive quality (six items). berceived behavioural control was constructed from two components: external control (two items) and internal control (three items).

For the other variables measured by means of a scale, the items were loaded on one factor (component) and were constructing one component.

had a positive attitude towards participation $(M=3.8)$, perceived a low level of social influence $(M=2.5)$, and a high level of behavioural control $(M=4.0)$. The disorders were perceived as serious $(M=4.4)$, and because there was no difference in perceived severity of CF and of HbPs, we took the perceived severity of both disorders together as one determinant. The mean knowledge score was 2.6 , but there was a large variation in the sum scores: $20 \%(82 / 418)$ had the minimum score of $0 ; 51 \%(212 / 418)$ had a score of 3 or higher; and 25\% (103/418) had the maximum score of 5 . The majority $(86 \% ; n=359)$ reported no feelings of stigmatisation (score $\leq 3$ ), with no difference between offer acceptors and offer decliners.

Offer acceptors had a slightly positive mean score for social influence, which was mainly because of the social influence they experienced from their partner (the mean score on this single statement was 3.8). Offer acceptors perceived more benefits of participation and more reproductive consequences of the test results than offer decliners. Furthermore, offer acceptors perceived a lower psychological effect of the offer and feelings of eugenics.

Offer decliners, although positive, had in general less positive/favourable mean scores than offer acceptors. They had a less positive attitude towards participation in the carrier testing, mainly because of their negative score on the item 'pleasant/unpleasant' (mean score 2.86), and they perceived less-behavioural control, because they more often stated that participation would cost them too much
Table 2 Sociodemographic characteristics of the 418 participants in the survey

\begin{tabular}{|c|c|c|}
\hline & $\begin{array}{c}\text { Offer -acceptors }{ }^{\mathrm{a}} \\
\text { (test intenders) }\end{array}$ & $\begin{array}{c}\text { Offer decliners } \\
\text { (test non-intenders) }\end{array}$ \\
\hline Number & 171 & 247 \\
\hline Men, $n(\%)$ & $85(50)$ & $120(49)$ \\
\hline \multicolumn{3}{|l|}{ Age, mean (range) } \\
\hline $\begin{array}{l}\text { Men } \\
\text { Women }\end{array}$ & $\begin{array}{l}32(23-47) \\
30(19-44)\end{array}$ & $\begin{array}{l}32(22-56) \\
29(20-42)\end{array}$ \\
\hline Married, $n(\%)$ yes & 57 & $67(27)$ \\
\hline With children, $n(\%)$ yes & $40(23)$ & $93(38)^{\star *}$ \\
\hline \multicolumn{3}{|l|}{ Level of education, $\mathrm{n}(\%)^{\mathrm{b}}$} \\
\hline $\begin{array}{l}\text { Low } \\
\text { Intermediate } \\
\text { High }\end{array}$ & $\begin{array}{l}17(10) \\
75(44) \\
79(46)\end{array}$ & $\begin{array}{c}9(4) \\
89(36) \\
149(60)^{*}\end{array}$ \\
\hline \multicolumn{3}{|l|}{ Ancestry, n (\%) } \\
\hline $\begin{array}{l}\text { Western origin } \\
\text { Non-Western immigrant }\end{array}$ & $\begin{array}{r}117(68) \\
54(32)\end{array}$ & $\begin{array}{r}179(72) \\
68(28)\end{array}$ \\
\hline
\end{tabular}

${ }^{a}$ There were no significant differences in these characteristics between the 143 test participants and the 28 test-intending non-participants. Therefore the data of the offer acceptors are presented in one column. bLow: primary school, lower level of secondary school, lower vocational training. Intermediate: higher level of secondary school, intermediate vocational training. High: higher vocational training, university.

${ }^{*} P<0.01 ;{ }^{*} P<0.001$. 
Table 3 Mean scores and proportion of participants in the survey who had a score above or below 3 (the neutral point) for determinants of the intention to participate or not to participate in the screening

\begin{tabular}{|c|c|c|c|c|c|}
\hline \multirow[b]{2}{*}{ Variables/scales ${ }^{a}$} & \multirow{2}{*}{$\begin{array}{l}\text { All }(\mathrm{n}=418) \\
\quad \text { Mean }\end{array}$} & \multicolumn{2}{|c|}{$\begin{array}{c}\text { Offer acceptors } \\
\text { (test- intenders) }(\mathrm{n}=171)\end{array}$} & \multicolumn{2}{|c|}{$\begin{array}{c}\text { Offer decliners } \\
\text { (test non-intenders) }(\mathrm{n}=247)\end{array}$} \\
\hline & & Mean & $\mathrm{n}(\% \geq 3)$ & Mean & $\mathrm{n}(\% \geq 3)$ \\
\hline & & & $\mathrm{n}(\% \leq 3)$ & & $\mathrm{n}(\% \leq 3)$ \\
\hline $\begin{array}{l}\text { Familiarity with disorders } \\
\text { Familiarity with carrier test(s) } \\
\text { Religion }\end{array}$ & $\begin{aligned} & 241(58) \\
& 64(15) \\
& 16(4)\end{aligned}$ & & $\begin{array}{l}94(55) \\
21(12) \\
7(4)\end{array}$ & & $\begin{aligned} 147 & (60) \\
43 & (17) \\
9 & (4)\end{aligned}$ \\
\hline
\end{tabular}

a Mean scores were based on a 5-point Likert scale. Except for 'impact of the offer', 'stigmatisation', and 'feelings of eugenics', (1) represents a negative/unfavourable score and (5) a positive/favourable score.

${ }^{\mathrm{b}}$ Knowledge about inheritance was calculated as a sum score, with a minimum of 0 and a maximum of 5 .

${ }^{*} P<0.05 ;{ }^{* *} P<0.01 ;{ }^{* * *} P<0.001$. Offer acceptors were compared with offer decliners on mean scores and on proportion of people with a score of 3 or above or a score of 3 or below (for 'impact of the offer', 'stigmatisation', and 'feelings of eugenics').

'effort' and 'time'. Offer decliners further perceived themselves less susceptible to be a carrier.

\section{Explaining intention to participate or not in the screening}

Among all survey participants, $29 \%$ of the variance in intention to participate in the current preconceptional CF and/or HbPs carrier testing, as a result of the stepwise hierarchical linear regression, was explained by 'attitude' (19\%), 'perceived behavioural control' (4\%), and 'social influence' (7\%) in the first step (see Table 4a). Including 'perceived severity of the disorders', 'perceived benefits', and 'perceived feelings of eugenics' in the second step explained another $3.3 \%$ of the variance. None of the sociodemographic variables in the third step explained any additional variance in intention. The total predictive value of the equation (steps $1-3)$ was $33 \%(P<0.001)$.

\section{Explaining actual test participation among offer acceptors}

Not all offer acceptors actually took part in the testing (Figure 2). Those who intended to participate, but who actually did not $(n=28)$, perceived less behavioural control than the test participants $(n=143)$ : mean score 4.3 versus 4.6 , respectively $(P=0.024)$, because participation would cost them too much effort and time. Furthermore, test participants were less familiar with the tests: 9\% $(13 / 143)$ versus $30 \%(8 / 27)(P<0.01)$, and they were also younger: mean age 30.5 versus 32.8 years $(P=0.026)$. In the regression analysis, the determinants of actual test participation among the 171 offer acceptors were less familiarity with the carrier test(s) and younger age, which together had a predictive power of $31 \%$ $(P<0.001)$ (data not shown).

\section{Explaining future intention among decliners of the current offer}

In total, $68 \%(167 / 247)$ of the offer decliners had a positive intention (score $>3$ on the future intention scale) to participate in the future in preconceptional CF and/or HbPs carrier screening if this became possible $(M=3.5)$. Offer decliners without children were even more positive than those who already had children: $74 \%(114 / 154)$ versus $57 \%(53 / 93)(P=0.004)$. The $32 \%(80 / 247)$ of the offer decliners who were not interested in participating in this kind of screening in the future (score $\leq 3$ ), compared with those who were interested, perceived significantly less social influence $(M=1.8$ versus $2.3(P<0.001))$; perceived less benefits from the screening $(M=2.5$ versus 4.1 $(P<0.001))$; would less often draw reproductive conse- 
Table 4a Regression analysis: determinants of intention to participate or not to participate in the current preconceptional carrier screening among all participants in the survey

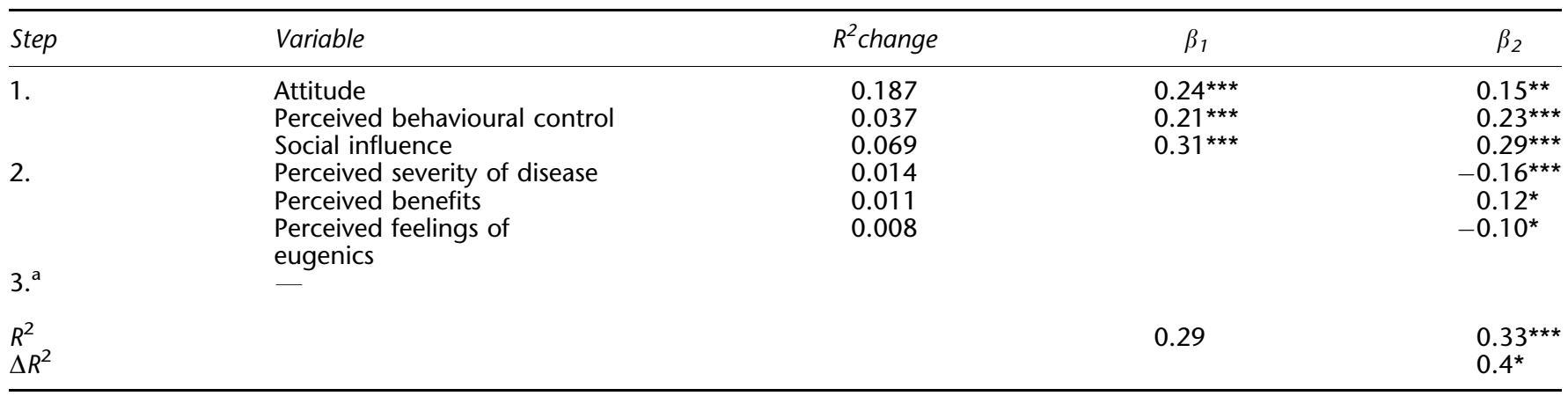

$N=418$. Variables are explained in Tables 1 and 2

$* * * P<001 ; * * P<0.01 ; * P<0.05$.

${ }^{a}$ None of the sociodemographic variables in the third step explained any additional variance in intention.

Table 4b Regression analysis: determinants of intention to participate in the future in preconceptional CF and/or HbPs carrier screening among decliners of the current offer

\begin{tabular}{|c|c|c|c|c|c|}
\hline Step & Variable & $R^{2}$ change & $\beta_{1}$ & $\beta_{2}$ & $\beta_{3}$ \\
\hline \multirow[t]{3}{*}{1.} & Attitude & 0.296 & $0.53^{* * *}$ & $0.46^{* *}$ & $0.45^{\star \star *}$ \\
\hline & Perceived behavioural control & 0.04 & $-0.18^{\star \star}$ & $-0.16^{\star \star}$ & $-0.11^{\star}$ \\
\hline & Social influence & 0.025 & $0.17^{*}$ & $0.17 * *$ & $0.12^{*}$ \\
\hline \multirow[t]{2}{*}{2.} & Perceived test consequences & 0.082 & & $0.31^{* * *}$ & $0.32^{* * *}$ \\
\hline & Knowledge about inheritance & 0.018 & & $-0.14^{\star *}$ & $-0.12^{\star}$ \\
\hline \multirow[t]{2}{*}{3.} & Ancestry & 0.019 & & & $0.19^{* * *}$ \\
\hline & Having children or not & 0.021 & & & $0.15^{\star *}$ \\
\hline$R^{2}$ & & & 0.36 & $0.46^{* \star *}$ & $0.50^{\star *}$ \\
\hline$\Delta R^{2}$ & & & & $0.10^{* *}$ & $0.04^{\star *}$ \\
\hline
\end{tabular}

$N=247$. Variables are explained in Tables 1 and 2 .

${ }^{* * *} P \leq 0.001 ;{ }^{* *} 0.001<P \leq 0.01 ;{ }^{*} 0.01<P \leq 0.05$.

quences from test results $(M=2.6$ versus $3.3(P<0.001))$; perceived more negative psychological effect (although still not much) $(M=2.7$ versus $2.3(P=0.004))$; perceived slightly more eugenetic feelings $(M=2.9$ versus 2.5 $(P=0.005))$, and had a higher knowledge score $(M=3.0$ versus $2.4(P=0.012))$. Offer decliners who did not intend to participate in this kind of screening in the future and who had children perceived a significantly lower susceptibility than those without children $(M=1.5$ versus 1.9 $(P=0.02))$.

The TPB determinants explained $36 \%$ of the variance in intention to participate in the future in preconceptional CF and/or HbPs carrier screening if this became possible (Table 4b) in the first step of the hierarchical linear regression analysis. 'Attitude' explained $30 \%$ of the variance $(P<0.001)$, followed by 'perceived behavioural control' (4.0\%) and 'social influence' (2.5\%) in the first step. Including 'perceived test consequences' and 'knowledge about inheritance' explained another $10 \%$ of the variance in the second step. 'Ancestry' and 'having children' explained another $4 \%$ in the third step, resulting in a total predictive value of the equation (steps 1-3) of $50 \%(P<0.01)$.

\section{Differences between Western and non-Western participants}

Non-Western participants were under-represented equally in the survey among offer acceptors and offer decliners, of whom $32 \%(54 / 171)$ and $28 \%(68 / 247)$ were of nonWestern origin, respectively. Table 5 presents the mean scores for the variables of Western and non-Western survey participants. Non-Western participants had less positive or less favourable scores, except for attitude and level of perceived benefits, for which there were no significant differences, and they more often expected that people would see them in a different light and that carriers would be discriminated (score $>3$ on 'stigmatisation'): $23 \%$ (28/ $122)$ versus $10 \%(31 / 296)(P=0.001)$. Non-Western offer decliners compared with Western offer decliners had a significantly higher mean score on the future intention scale: $M=3.8$ versus $3.4(P=0.011)$, and $75 \%(51 / 68)$ and 
Table 5 Mean scores for determinants of intention to participate or not to participate in the current screening among Western and non-Western participants in the survey

\begin{tabular}{|c|c|c|}
\hline \multirow[b]{2}{*}{ 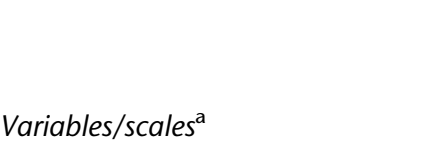 } & \multicolumn{2}{|c|}{ Ancestry } \\
\hline & $\begin{array}{l}\text { Western } \\
\text { origin } \\
(n=296)\end{array}$ & $\begin{array}{c}\text { Non-Western } \\
\text { origin } \\
(n=122)\end{array}$ \\
\hline \multicolumn{3}{|l|}{ Theory of Planned Behaviour } \\
\hline Attitude & 3.7 & 3.8 \\
\hline Social influence & 2.3 & $3.0 * * *$ \\
\hline Perceived behavioural control & 4.4 & $3.9^{* * *}$ \\
\hline \multicolumn{3}{|l|}{ Other variables } \\
\hline Perceived benefits & 3.8 & 4.0 \\
\hline $\begin{array}{l}\text { Perceived consequences of test } \\
\text { results }\end{array}$ & 3.3 & $2.9^{\star \star \star}$ \\
\hline Severity of disorders & 4.5 & $4.0^{\star * *}$ \\
\hline Perceived susceptibility & 1.6 & $2.2^{\star \star *}$ \\
\hline Knowledge about inheritance ${ }^{\mathrm{b}}$ & 2.9 & 1.7 \\
\hline Impact of the offer & 2.1 & $2.4^{*}$ \\
\hline Stigmatisation & 2.1 & $2.3^{* *}$ \\
\hline \multirow[t]{2}{*}{ Feeling of eugenics } & 2.3 & $2.9^{\star \star *}$ \\
\hline & $n$ (\% yes) & $n$ (\% yes) \\
\hline Familiarity with disorders & $182(61)$ & $58(48)^{*}$ \\
\hline Familiarity with carrier test(s) & $49(17)$ & $15(12)$ \\
\hline Religion & $9(3)$ & $7(6)$ \\
\hline
\end{tabular}

a Mean scores were based on a 5-point Likert scale. Except for 'impact of the offer', 'stigmatisation', and 'feelings of eugenics', (1) represents a negative or unfavourable and (5) a positive or favourable score.

${ }^{\mathrm{b}}$ Knowledge on inheritance was calculated as a sum score, with a minimum of 0 and a maximum of 5 .

${ }^{*} P<0.05 ;{ }^{* *} P<0.01 ;{ }^{* * *} P<0.001$. Western participants in the survey were compared with non-Western participants.

$65 \%(116 / 179)$, respectively, intended to participate in future screening if this became possible $(P=0.08)$.

\section{Discussion}

\section{Determinants of intention and participation}

In general, we found that the large majority of both those who accepted and those who declined the offer were in favour of participation in preconceptional CF and HbPs carrier screening. It is clear that having a positive attitude alone is not sufficient for actual test participation. Or stated otherwise: having a positive intention not automatically leads to participation: what people say is not always what they do. In this study the TPB, which already has been used successfully in cervical cancer and cholesterol-screening studies, ${ }^{33,34}$ was found to offer a useful framework for exploring the determinants of participation in preconceptional CF and/or HbPs carrier couple screening. The TPB determinants (attitude, social norm, and perceived behavioural control) explained a considerable amount of the total variance in the intention to participate in the current carrier testing (29\%), and in a futurescreening programme (36\%). We showed that perceived behavioural control indeed influenced the behaviour in itself, as is seen in the TPB (Figure 1): ${ }^{27}$ eligible invitees with a positive attitude, but who stated that participation would cost them too much time and effort, refrained from current test participation. Nevertheless, $68 \%$ of the decliners of the current offer had a positive intention to participate in future in this kind of screening if it became possible. But again, this hypothetical situation might differ from what they will really do, when the screening would be offered routinely.

Compared with the findings of earlier (preconceptional) carrier-screening studies, no major differences were found in the determinants that were associated with accepting or declining the screening (see Table 4a). ${ }^{15-17,19-23,25}$ Factors influencing acceptance in this study were a more positive attitude, perceiving more behavioural control, perceiving some social influence, and perceiving more benefits. Both disorders were equally perceived as severe. A strong perception of severity was found to be a declining factor in this study, whereas there was no significant difference between offer acceptors and offer decliners. Earlier, a strong perception of severity has been described not only as a declining factor, ${ }^{15,25}$ but also as a factor for acceptance, ${ }^{15,21,35}$ which poses questions about its value as a determinant of intention to participate. Very few of the offer acceptors as offer decliners perceived any feelings of eugenics, but offer decliners perceived more feelings of eugenics, which in this study seemed to be a smalldeclining factor. Furthermore, although there was a large variation, the survey participants generally had a low mean level of knowledge about inheritance, which has earlier been reported as a reason for declining. ${ }^{15-17}$ Fear for needles seemed to be the most important reason for declining to participate in a Tay-Sachs screening programme among school-aged Ashkenazi Jews, ${ }^{19}$ but it was of no importance in our study.

Although $8 \%$ of the offer acceptors stated that they perceived limited benefits from participation, and $23 \%$ of them reported that they would draw no reproductive consequences from the test results (see Table 3), a finding also reported by Poppelaars et al., ${ }^{21}$ their intention to participate might be due to social pressure, as they perceived more social influence from their partners in this study. Otherwise, they might just want to know their carrier status, as reported by Ahmed et al. ${ }^{20}$

The most important reason for having a negative future intention among $32 \%$ of the offer decliners are a less positive attitude towards abortion, and the fact that they would not change reproductive behaviour, which has been reported earlier. ${ }^{15}$ In addition, they more often already had children, which earlier was a decline factor in CF carrier screening as well. ${ }^{15,22,36,37}$ However, in this study, only those invitees who were planning a pregnancy were included, and those who had regarded their family as complete yet were not. Nevertheless, our data support the idea that people who already have unaffected offspring are 
less inclined to perceive their future children at risk for $\mathrm{CF}$ and/or HbPs. ${ }^{36}$ In this study, namely, survey participants who already had children and who did not intend to participate in the future in this kind of screening programme if it became possible less often thought that they might be a carrier than those who had no children.

Feelings of stigmatisation or discrimination have been mentioned and feared as undesirable side effects of genetic screening. ${ }^{10,38}$ However, in this study, such feelings were not an important issue, which has been reported as a reason for acceptance in earlier studies. ${ }^{15,17}$

\section{Differences between Western and non-Western participants}

Although there was an under-representation of non-Western compared with Western survey participants (29 versus 71\%), non-Western survey participants had an equally positive attitude towards test participation, but Western survey participants perceived a higher level of behavioural control. A general failure to facilitate informed choices among ethnic minority groups, as suggested by Dormandy et al., ${ }^{24}$ may have resulted in a lower uptake among non-Western immigrants, as well, because all material was available only in Dutch, which could have resulted in limited opportunities among non-Western invitees. In addition, although in general only a minority of $14 \%$ of the survey participants stated that they thought that carriers might be discriminated, non-Western survey participants were significantly more among them. Conclusively, feelings of stigmatisation might also have been present among non-Western non-respondents. Furthermore, the non-Western survey participants would draw reproductive consequences from the test results less often, which is in accordance with the Ahmed et al. ${ }^{20}$ study, in which participants in prenatal $\beta$-thalassemia screening mostly opted for prenatal diagnosis, because they just 'wanted to know' and not because they would opt for abortion if the child was affected. Pregnancy termination is accepted, though, by a major proportion of non-Western populations as an option in prenatal screening for HbPs. ${ }^{20,39}$

\section{Limitations}

This study has some limitations, one of which is the limited response: $85 \%$ did not return the reply form and we have no information about these non-respondents. However, in a telephone survey among a sample of nonrespondents $(n=201)$, there was no difference in the proportion of invitees who belonged to the target population between the respondents and non-respondents (data not shown), which has been estimated to be 36 vs 33\% (NS). Furthermore, in our project the actual test uptake among invitees who belonged to the target population was $3 \% .{ }^{14}$ This uptake was not in accordance with the reported uptake of $25 \%$ in an earlier preconceptional CF carrier couple screening study in the Netherlands, ${ }^{5}$ neither with the findings that the majority of prospective parents favoured a routine offer of preconceptional couple screening and intended to participate in this kind of screening if this would become a standard offer. ${ }^{17,21}$ This low uptake may reflect a lack of interest among prospective parents in this kind of screening, as Clayton et al. ${ }^{16}$ suggested in a population-based CF carrier-screening programme in which there was also a low uptake. Otherwise, it may be questioned whether a lack of interest is the only explanation for low uptake in a screening programme with regard to the results of this study, in which practical barriers form a major declining factor for test participation in the carrierscreening programme. The results therefore might not be generalisable to the entire target population. Nevertheless, the number of 418 participants in the survey is more than sufficient to answer our research question to identify which determinants influence participation or nonparticipation.

There were also practical limitations related to the study design. The limited period of time that was available for making an appointment with the GP, the fact that the partner also had to be present at this pre-test consultation, and the fact that test participation was not possible without survey participation might all have resulted in non-participation in the testing. Furthermore, the written study material was available only in Dutch. The fact that the tests were offered free of charge made it impossible to study whether paying for these kinds of screening tests would have been a reason for declining the offer, as found in other studies. ${ }^{15}$ Furthermore, the fact that the test-intending non-participants completed their questionnaires after they heard that actual test participation was no longer possible for them according to the study design might have influenced their answers.

Finally, we studied an offer of preconceptional ancestrybased carrier screening for CF and HbPs as a model for preconceptional carrier screening for other genetic disorders that are more or less common among different population groups. Nevertheless, results might be different if carrier screening is offered for other disorders that are perceived, for example, as less or more severe, or if carrier screening for a large number of disorders is offered together.

\section{Conclusion and implications}

In this study, a unique offer of combined ancestry-based preconceptional CF and/or HbPs carrier couple screening was, in general, valued as positive and desirable among people of Western and non-Western origin, and among those who accepted and those who declined the current offer of carrier testing. There were no major feelings of stigmatisation or discrimination. A large proportion of those who declined to participate in the current testing intended to participate in the future if it became possible. The amount of effort and time needed for participation was an important reason for declining actual test participation, 
and the fact that test participation was conditional on survey participation must also have resulted in a lower uptake. Although there was not a high uptake in this $\mathrm{s}$ tudy, the results are similar to those reported in earlier studies on factors influencing decisions to accept or decline preconceptional carrier screening in and outside the Netherlands. ${ }^{15}$ This study, therefore, contributes to the identification of factors that influence the decision to accept or decline preconceptional carrier screening, and showed that there must be less barriers if we are to promote reproductive decision-making, especially among prospective parents who are of non-Western origin.

\section{References}

1 Bobadilla JL, Macek Jr M, Fine JP, Farrell PM: Cystic fibrosis: a worldwide analysis of CFTR mutations - correlation with incidence data and application to screening. Hum Mutat 2002; 19: 575-606.

2 Estivill X, Bancells C, Ramos C: Geographic distribution and regional origin of 272 cystic fibrosis mutations in European populations. The Biomed CF mutation analysis consortium. Hum Mutat 1997; 10: 135-154.

3 Angastiniotis M, Modell B: Global epidemiology of hemoglobin disorders. Ann NY Acad Sci 1998; 850: 251-269.

4 Weatherall DJ, Clegg JB: Inherited haemoglobin disorders: an increasing global health problem. Bull World Health Organ 2001; 79: $704-712$.

5 Henneman L, Bramsen I, Van Kempen L et al: Offering preconceptional cystic fibrosis carrier couple screening in the absence of established preconceptional care services. Community Genet 2003; 6: 5-13.

6 Leib JR, Gollust SE, Hull SC, Wilfond BS: Carrier screening panels for Ashkenazi Jews: is more better? Genet Med 2005; 7: 185-190.

7 Mitchell JJ, Capua A, Clow C, Scriver CR: Twenty-year outcome analysis of genetic screening programs for Tay-Sachs and betathalassemia disease carriers in high schools. Am J Hum Genet 1996; 59: 793-798.

8 Poppelaars FA, Henneman L, Ader HJ et al: How should preconceptional cystic fibrosis carrier screening be provided? Opinions of potential providers and the target population. Community Genet 2003; 6: 157-165.

9 ACOG (American College of Obstetricians and Gynecologists) committee opinion: Genetic screening for hemoglobinopathies, number 238, July 2000. Committee on Genetics. Int J Gynaecol Obstet 2001; 74: 309-310.

10 European Society of Human Genetics: Population genetic screening programmes: technical, social and ethical issues. Eur J Hum Genet 2003; 11 (Suppl 2): S5-S7.

11 Grody WW, Cutting GR, Klinger KW, Richards CS, Watson MS, Desnick RJ: Laboratory standards and guidelines for population-based cystic fibrosis carrier screening. Genet Med 2001; 3: 149-154.

12 Markel H: The stigma of disease: implications of genetic screening. Am J Med 1992; 93: 209-215.

13 McQueen MJ: Some ethical and design challenges of screening programs and screening tests. Clin Chim Acta 2002; 315: 41-48.

14 Lakeman P: Preconceptional carrier couple screening for cystic fibrosis and hemoglobinopathies. An ancestry-based offer in a multi-ethnic society. Thesis, 2008.

15 Chen LS, Goodson P: Factors affecting decisions to accept or decline cystic fibrosis carrier testing/screening: a theory-guided systematic review. Genet Med 2007; 9: 442-450.

16 Clayton EW, Hannig VL, Pfotenhauer JP, Parker RA, Campbell III PW, Phillips III JA: Lack of interest by nonpregnant couples in population-based cystic fibrosis carrier screening. Am J Hum Genet 1996; 58: 617-627.
17 Henneman L, Bramsen I, Van der Ploeg HM et al: Participation in preconceptional carrier couple screening: characteristics, attitudes, and knowledge of both partners. J Med Genet 2001; 38: 695-703.

18 Marteau TM: Population screening for cystic fibrosis: a research agenda for the next 10 years. Am J Med Genet 2000; 93: 205-206.

19 Gason AA, Metcalfe SA, Delatycki MB et al: Tay Sachs disease carrier screening in schools: educational alternatives and cheekbrush sampling. Genet Med 2005; 7: 626-632.

20 Ahmed S, Green JM, Hewison J: Attitudes towards prenatal diagnosis and termination of pregnancy for thalassaemia in pregnant Pakistani women in the North of England. Prenat Diagn 2006; 26: 248-257.

21 Poppelaars FA, Henneman L, Ader HJ et al: Preconceptional cystic fibrosis carrier screening: attitudes and intentions of the target population. Genet Test 2004; 8: 80-89.

22 Loader S, Caldwell P, Kozyra A et al: Cystic fibrosis carrier population screening in the primary care setting. Am J Hum Genet 1996; 59: 234-247.

23 Tambor ES, Bernhardt BA, Chase GA et al: Offering cystic fibrosis carrier screening to an HMO population: factors associated with utilization. Am J Hum Genet 1994; 55: 626-637.

24 Dormandy E, Michie S, Hooper R, Marteau TM: Low uptake of prenatal screening for Down syndrome in minority ethnic groups and socially deprived groups: a reflection of women's attitudes or a failure to facilitate informed choices? Int J Epidemiol 2005; 34: 346-352.

25 Shiloh S, Ilan S: To test or not to test? Moderators of the relationship between risk perceptions and interest in predictive genetic testing. J Behav Med 2005; 28: 467-479.

26 Singer E, Antonucci T, Van Hoewyk J: Racial and ethnic variations in knowledge and attitudes about genetic testing. Genet Test 2004; 8: $31-43$.

27 Ajzen I: The theory of planned behaviour. Organ Behav Hum 1991; 50: $179-211$.

28 Sheeran P, Conner M, Norman P: Can the theory of planned behavior explain patterns of health behavior change? Health Psychol 2001; 20: 12-19.

29 Lakeman P, Henneman L, Bezemer PD, Cornel MC, Kate LP: Developing and optimizing a decisional instrument using selfreported ancestry for carrier screening in a multi-ethnic society. Genet Med 2006; 8: 502-509.

30 Statistics Netherlands: Voorburg/Heerlen, 2008. Available at www.cbs.nl on 1 November 2008.

31 Stronks K, Ravelli AC, Reijneveld SA: Immigrants in the Netherlands: equal access for equal needs? J Epidemiol Community Health 2001; 55: 701-707.

32 Newman JE, Sorenson JR, DeVellis BM, Cheuvront B: Gender differences in psychosocial reactions to cystic fibrosis carrier testing. Am J Med Genet 2002; 113: 151-157.

33 Deskins S, Harris CV, Bradlyn AS et al: Preventive care in Appalachia: use of the theory of planned behavior to identify barriers to participation in cholesterol screenings among West Virginians. J Rural Health 2006; 22: 367-374.

34 Orbell S, Hagger M, Brown V, Tidy J: Comparing two theories of health behavior: a prospective study of noncompletion of treatment following cervical cancer screening. Health Psychol 2006; 25: 604-615.

35 Ahmed S, Bekker H, Hewison J, Kinsey S: Thalassaemia carrier testing in Pakistani adults: behaviour, knowledge and attitudes. Community Genet 2002; 5: 120-127.

36 Mennie ME, Gilfillan A, Compton M et al: Prenatal screening for cystic fibrosis. Lancet 1992; 340: 214-216.

37 Honnor M, Zubrick SR, Walpole I, Bower C, Goldblatt J: Population screening for cystic fibrosis in Western Australia: community response. Am J Med Genet 2000; 93: 198-204.

38 Green JM, Hewison J, Bekker HL, Bryant LD, Cuckle HS: Psychosocial aspects of genetic screening of pregnant women and newborns: a systematic review. Health Technol Assess 2004; 8: iii, ix-iii, 109.

39 Giordano PC, Dihal AA, Harteveld CL: Estimating the attitude of immigrants toward primary prevention of the hemoglobinopathies. Prenat Diagn 2005; 25: 885-893. 